\title{
Photoacoustics of single aerosol droplets immobilised by counter- propagating optical tweezers
}

\section{Conference Paper}

\section{Author(s):}

Diveky, Matus (D); Gleichweit, Michael (D); Roy, Sandra; Bartalucci, Ettore; Signorell, Ruth (D)

\section{Publication date:}

2020-08

\section{Permanent link:}

https://doi.org/10.3929/ethz-b-000444036

\section{Rights / license:}

In Copyright - Non-Commercial Use Permitted

\section{Originally published in:}

Optical Trapping and Optical Micromanipulation XVII 11463, https://doi.org/10.1117/12.2566041

\section{Funding acknowledgement:}

177479 - Fundamentals of Aerosol Photoacoustic Spectroscopy (SNF)

172472 - Phase Transitions of Ultrafine Aerosol Particles: Condensation, Freezing, and Metal Formation in Confined Systems (SNF) 


\section{Photoacoustics of single aerosol droplets immobilised by counter- propagating optical tweezers}

Diveky, Matus, Gleichweit, Michael, Roy, Sandra, Bartalucci, Ettore, Signorell, Ruth

Matus E. Diveky, Michael J. Gleichweit, Sandra Roy, Ettore Bartalucci, Ruth Signorell, "Photoacoustics of single aerosol droplets immobilised by counterpropagating optical tweezers," Proc. SPIE 11463, Optical Trapping and Optical Micromanipulation XVII, 1146316 (20 August 2020); doi: 10.1117/12.2566041

SPIE. Event: SPIE Nanoscience + Engineering, 2020, Online Only 


\title{
Photoacoustics of single aerosol droplets immobilised by counter-propagating optical tweezers
}

\author{
Matus E. Diveky*, Michael J. Gleichweit, Sandra Roy, Ettore Bartalucci, and Ruth Signorell \\ Laboratory of Physical Chemistry, Department of Chemistry and Applied Biosciences, ETH \\ Zürich, Vladimir-Prelog-Weg 2, CH-8093, Zürich, Switzerland
}

\begin{abstract}
In this contribution we discuss the influence of relative humidity on photoacoustic measurements from both an experimental and theoretical perspective. We present a refined model of the photoacoustic (PA) signal that accounts for elevated particle temperatures and different levels of relative humidity. We use this new model together with the photoacoustic data collected with our photothermal single-particle spectrometer (PSPS) to retrieve the mass accommodation coefficients of water on organic aerosol particles. The single-particle nature of our experiments is achieved by employing counter-propagating tweezers. Furthermore, we investigate the influence of relative humidity on the eigenfrequency of the PA cell.
\end{abstract}

Keywords: photoacoustic spectroscopy, optical trapping, counter-propagating tweezers, mass accommodation coefficient, aerosols, relative humidity

\section{INTRODUCTION}

Aerosol particles are ubiquitous in the atmosphere and thus influence the global climate ${ }^{1-5}$ and human health. ${ }^{6-9}$ Light absorption and scattering by aerosol particles influences the climate directly, while their ability to behave as cloud-condensation nuclei govern the cloud formation, by which they indirectly influence the climate and weather patterns. Aerosol particles represent a highly complex system to study due to their different compositions (ranging from organic droplets to inorganic salts), wide size distributions (nanometre to micrometre range), different phases and various morphologies. Strong coupling between the gas and condensed phase influences the aerosols' physical-chemical properties on a variety of timescales, ranging from seconds to days. ${ }^{10-12}$ As a result, aerosols represent one of the major uncertainty in current climate modelling. ${ }^{1-5}$ Due to the abundance of water vapour in the atmosphere, water uptake by aerosol particles plays a key role in defining the overall effect of aerosols on the climate. The uptake of water by various organic and inorganic aerosols influences their composition, size and ultimately their scattering albedo (the ratio of the scattering coefficient to the total extinction coefficient). As a result, studies of water transport between the gas and aerosol phase have received a lot of attention recently.

Upon collision with a liquid or solid surface, gas phase molecules can either reflect from the surface or get adsorbed and therewith enter the corresponding condensed phase (heterogeneous uptake of water). The competition between the reflection and adsorption governs the ability of aerosols to nucleate cloud droplets and thereby controls the droplet number density. ${ }^{1,2,5,13,14}$ The fraction of gas-phase molecules that stick to the surface upon collision is described by the mass accommodation coefficient $\alpha_{\mathrm{M}},{ }^{15-17}$ which is a probability value and takes on values between 0 and 1. It was defined as early as 1859 by Maxwell in his papers on the dynamical theory of gases ${ }^{18}$ and, under microscopic reversibility, equals the evaporation coefficient. ${ }^{16,19}$ Mass accommodation coefficients are important for accurate modelling of the kinetic growth rates of aerosol particles induced by the uptake of gas phase species, such as water. Reliable values of $\alpha_{\mathrm{M}}$ are crucial in the areas of climate modelling, ${ }^{1,20}$ aerosol drug delivery ${ }^{21,22}$ and many industrial applications, such as ink-jet printing or electrospraying. However, accurate values of mass accommodation coefficients are still lacking for many systems. For example, the values of $\alpha_{\mathrm{M}}$ for the well-studied system of water on water span orders of magnitude. ${ }^{23-25}$ Consequently, it is important to design new experimental techniques that can be used to retrieve reliable values of the mass accommodation coefficients.

${ }^{*}$ Corresponding author. E-mail address: matus.diveky@phys.chem.ethz.ch 
Photoacoustic (PA) spectroscopy is a highly sensitive absorption technique used routinely in research field campaigns ${ }^{26-31}$ and in laboratories, ${ }^{32-37}$ for example, to quantify the absorption or monitor the concentration of specific gas phase species or aerosol particles. The main principle of PA spectroscopy is conversion of light energy into acoustic energy (sound). This is achieved by using intensity-modulated laser light that is absorbed by the studied system, which in turn induces an energy flux from the particle to the surrounding gas phase (Figure 1). One pathway of energy exchange with the ambient gas is through direct collisions between the surrounding gas and the particle surface (heat flux). Another pathway involves evaporation and condensation of volatile species (mass flux). The overall energy flux from and to the particle gives rise to the formation of pressure waves that can be measured using a microphone or a tuning fork. ${ }^{38-43}$ The mass flux is dependent on the mass accommodation coefficient. Thus, by performing the photoacoustic measurements at different levels of relative humidity, the values of the mass accommodation coefficients of water on organic aerosol can be retrieved.

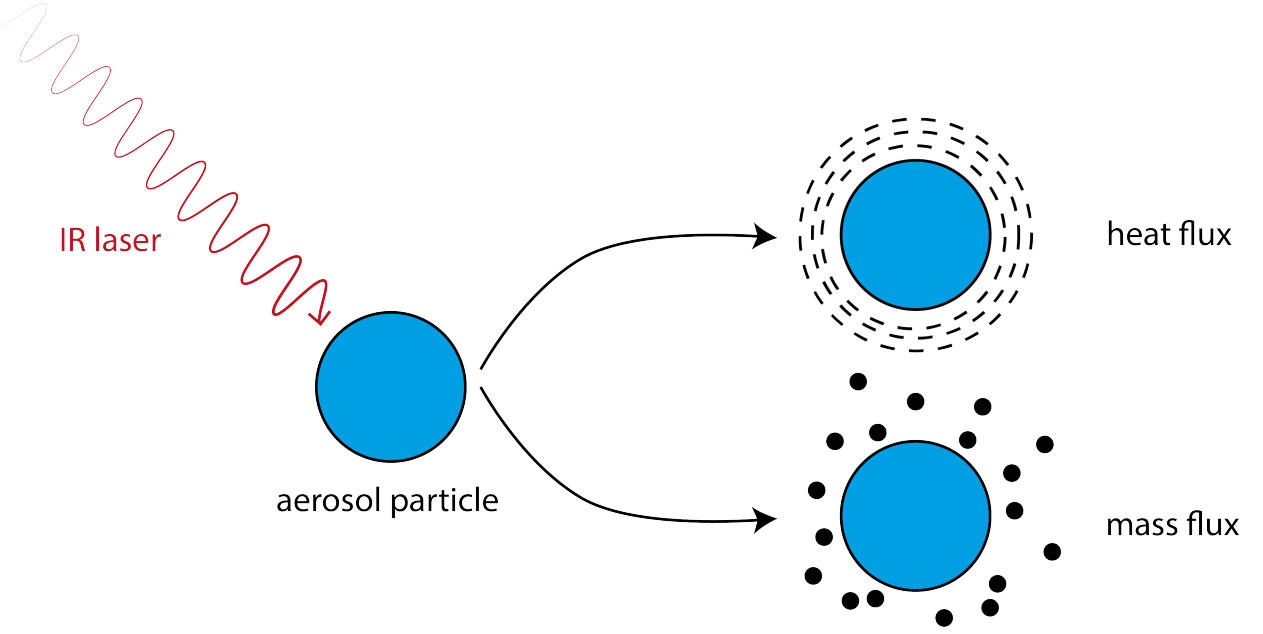

Figure 1. An illustration of the photoacoustic effect. An aerosol particle (blue) is irradiated with an intensity-modulated IR laser (red) which results in heat flux and mass flux, both of which constitute the photoacoustic signal.

In order to study the properties of aerosols on a fundamental level, single-particle methods are often employed. Studying single particles as opposed to ensembles avoids ensemble averaging effects ${ }^{44-46}$ and allows for size-specific measurements performed in tightly controlled environmental conditions (temperature and relative humidity). Optical traps ${ }^{47-52}$ are routinely used to levitate a single droplet in air, as they allow for convenient working distance, tight confinement and do not introduce any morphological changes to the trapped droplets. Optical trapping has been used in the past, for example, to measure refractive indices of aerosols, ${ }^{53-59}$ collect Raman spectra ${ }^{60-62}$ or measure viscosity ${ }^{63}$ and surface tension. ${ }^{64}$ Cremer et al. developed the first single-particle photoacoustic spectrometer, which allows for size specific PA measurements on optically trapped droplets. ${ }^{32,65,66}$

In our previous work, we investigated the influence of relative humidity on the PA signal ${ }^{33,34,67}$ which has been long discussed in the literature. ${ }^{27,29,35,68}$ Using the relative humidity dependence of the PA signal, we were also able to retrieve the mass accommodation coefficients of water on organics. ${ }^{69,70}$ In this work we further investigate the influence of relative humidity on the acoustic properties of the PA cells and we present a new theoretical model, which allows for simulations of particles with elevated temperatures at different levels of relative humidity. We use this newly revised model to retrieve the mass accommodation coefficients from our previously collected experimental data. ${ }^{33,34}$

\section{METHODS}

\subsection{Experimental}

The measurements were performed using our single-particle photoacoustic set-up, ${ }^{32}$ shown in Figure 2 . Here, only a brief description of the set-up is provided, as the details can be found elsewhere. ${ }^{33,34,69}$ We use a 
$532 \mathrm{~nm}$ laser (Laser Quantum, Opus, continuous wave) to build a counter-propagating optical trap by first splitting the beam into two equal parts using a polarisation beam splitter cube (PBC, PBS201 Thorlabs). The two trapping laser beams (each $\sim 250 \mathrm{~mW}$ ) are focused inside the PA cell with a facing pair of aspherical lenses $(75 \mathrm{~mm}$, ASL10142 Thorlabs). An IR laser (9.47 $\mu \mathrm{m}$ diode laser from AdTech Optics) is focused inside the PA cell by a ZnSe lens $(75.0 \mathrm{~mm}$, LA7660-G, Thorlabs), perpendicular to the direction of the trapping laser.

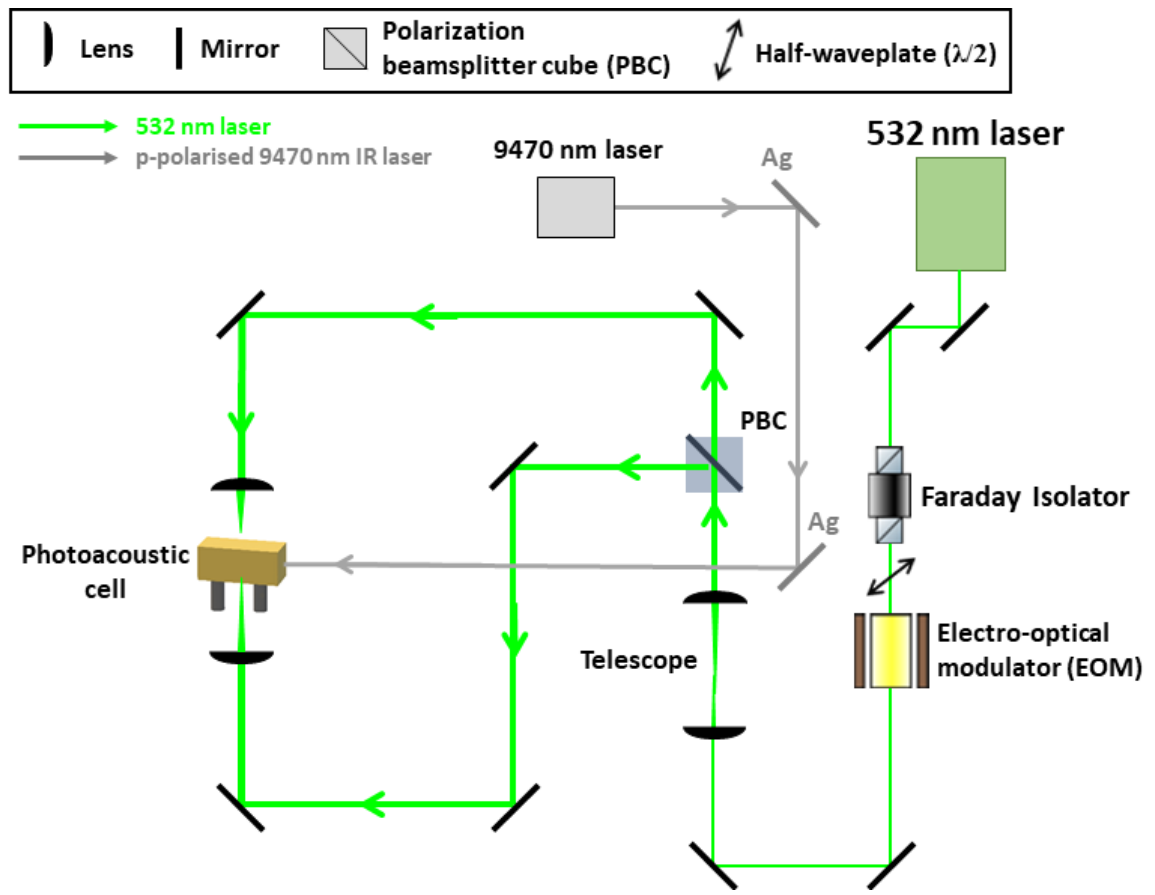

Figure 2. A sketch of the experimental set-up, showing the trapping laser (green), photoacoustic laser (gray) and the PA cell (yellow).

The photoacoustic cell consists of an acoustic resonator $(4 \mathrm{~cm}$ long and $4 \mathrm{~mm}$ in diameter) attached to two buffer volumes $(1.5 \mathrm{~cm}$ long and $3 \mathrm{~cm}$ in diameter) at either side of the resonator. The acoustic resonator is designed such that it amplifies longitudinal acoustic modes at $4000 \mathrm{~Hz}$. The buffer volumes behave as noisecancellers, thus their design strongly influences their performance. ${ }^{71,72}$ The signal is generated by illuminating a trapped particle by the intensity-modulated IR laser, which results in a photoacoustic effect. The sound wave produced by the trapped particle is measured using an electret microphone (Knowles Electronics, EK-23133C36), which is located directly below the particle at an antinode of the excited acoustic mode. The microphone signal is amplified by a self-made amplifier and detected using a lock-in amplifier (Zurich Instruments, $500 \mathrm{kHz}$ MFLI) that demodulates the input signal at $4000 \mathrm{~Hz}$.

The PA cell allows for optical trapping, photoacoustic measurements and light scattering measurements to be carried out simultaneously. The scattered $532 \mathrm{~nm}$ light is collected using a microscope objective (Mitutoyo, M Plan Apo 20x Objective), which is located on top of the cell, and then projected onto a CMOS camera, photodiode (Hamamatsu, S2506-02) and a quadrant photodiode (Hamamatsu, S5980). The camera signal is used for visual control of the particle, the photodiode signal is used for size determination ${ }^{52}$ and the quadrant photodiode is used for feedback stabilisation of the trapped particle. ${ }^{33}$ The feedback loop drives the electro-optical modulator (EOM, 350-50-01, ConOptics) that is attached to an adjustable mount (M102A, ConOptics) for a perfect alignment. A home-built proportional-integral-derivative (PID) controller adjusts the voltage applied to the EOM depending on the signal from the quadrant photodiode, effectively altering the polarisation of the trapping beam prior to the PBC. As a consequence, the respective powers of the two beams after passing through the polarisation beamsplitter are changed. This feedback loop greatly stabilises the position of the trapped particle and guarantees a consistent trapping position for differently sized particles. 
The aerosol particles composed of tetraethylene glycol (TEG) are produced using a medical nebuliser (Pari LC Sprint). TEG serves as a good model material for hydrophilic organic aerosols, although ethylene glycols themselves are not an important component of the particulate matter in the atmosphere. A pulse of generated aerosol droplets is brought into the PA cell, where one particle gets trapped in the focal region of the trapping beams. Nitrogen gas $(20 \mathrm{sccm})$ is used to remove the excess of aerosols and to control the relative humidity. Measurements on TEG particles were performed at different levels of relative humidity, ranging from $11 \%$ to $93 \%$ achieved by mixing dry and wet flows of nitrogen. The analysis of the photoacoustic and scattering signals from TEG particles enables us to retrieve the mass accommodation coefficient which are presented in Section 3.3.

In order to investigate the acoustic properties of the PA cells, measurements on the background signals were collected. The background signals most likely originate from the aerosol deposition on the $\mathrm{BaF}_{2}$ windows, through which the IR laser enters the PA cell. During these measurements, the PA cell contained no trapped particle. Figure 3 shows an eigenfrequency sweep of our PA cell. We observe an acoustic resonance at $\sim 3900 \mathrm{~Hz}$. The PA amplitude is fitted using a Lorentzian function (Figure 3 right), from which the eigenfrequency of the acoustic resonator can be retrieved. Similarly, the first derivative of the PA phase can be fitted with a Lorentzian.
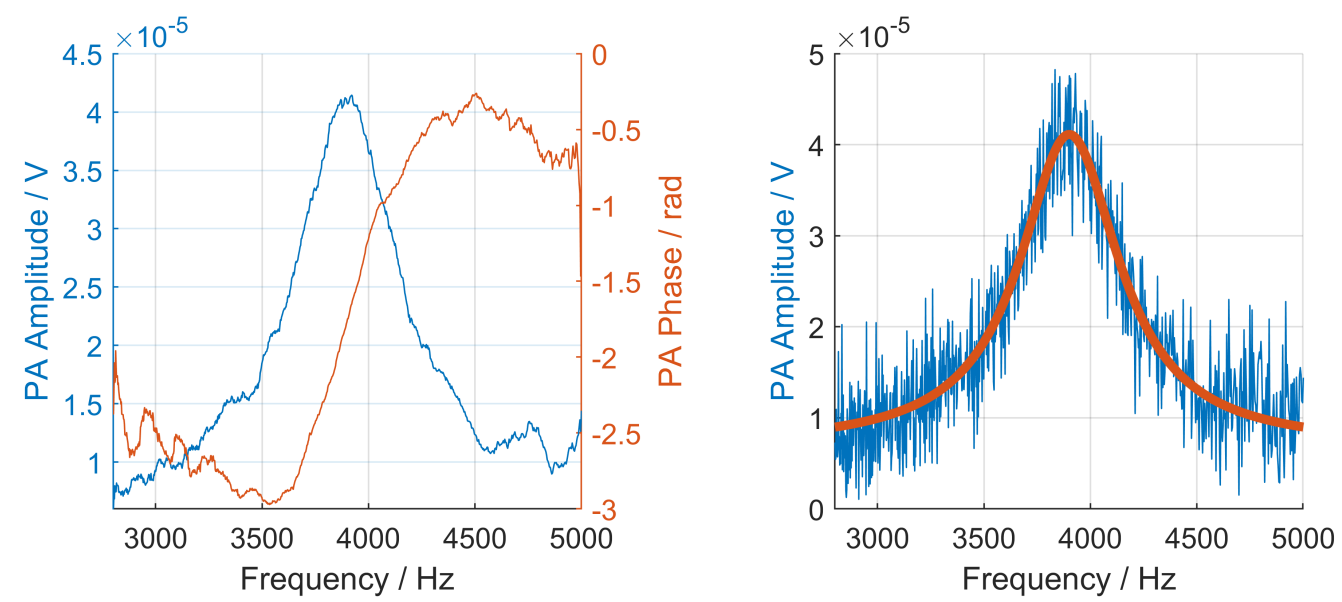

Figure 3. Left: an eigenfrequency sweep of the PA cell at $45 \% \mathrm{RH}$, showing the PA amplitude and phase components. The PA amplitude and phase are clearly related, with the maxima in the PA amplitude coinciding with the inflexion point in the PA phase. Right: raw experimental PA amplitude data fitted with a Lorentzian function.

\subsection{Modelling}

Our model is based on the theory proposed by Kulmala et al., ${ }^{25,73-76}$ which was also adopted by Murphy ${ }^{77}$ and successfully used in our former work. ${ }^{33,34,69}$ It comprises a locally fixed, spherical particle composed of aqueous TEG with its composition varying with relative humidity, and an IR laser tuned to be absorbed efficiently by TEG, trapped inside an acoustic resonator with constant ambient temperature $T_{\infty}$, relative humidity $\varphi$ and pressure $p$. The IR laser is intensity-modulated in a sinusoidal fashion, thus making the heating of the particle periodic as well. The equation for the energy conservation can be expressed as:

$$
E(t, \omega)=Q(r, T)+I\left(r, x_{a}(\varphi)\right) L+m_{\mathrm{p}} c_{\mathrm{p}, \mathrm{a}}\left(x_{a}(\varphi)\right) \frac{\partial T}{\partial t}
$$

where $T$ is the particle temperature, $t$ is time, $\omega$ is the angular frequency of the IR laser, $Q(r, T)$ is the heat flux (HF) away from the particle, $I\left(r, x_{\mathrm{a}}(\varphi)\right)$ is the mass flux (MF) away from the particle, $r$ is the particle radius, $L$ and $x_{a}(\varphi)$ are latent heat and molar concentration in the particle of the evaporating species, $m_{\mathrm{p}}$ and $c_{\mathrm{p}, \mathrm{a}}$ are mass and specific heat capacity of the particle. The absorbed IR-light represents the source term in the differential equation and is given by:

$$
E(t, \omega)=E_{0}\left(e^{-i \omega t}+1\right)
$$


It oscillates between 0 and $2 E_{0}$, where the absorbed energy density $E_{0}$ depends on the laser power $I_{0}$ and the particles absorption cross-section $C_{\mathrm{abs}}\left(r, x_{\mathrm{a}}(\varphi)\right)$. Integration of the one-dimensional form of Fourier's law for thermal conduction over a spherical particle boundary yields the heat flux $Q$ as a function of the particle's temperature in its simplest form:

$$
Q(T) \approx 4 \pi r K\left(T-T_{\infty}\right)
$$

where $K$ is the heat conductivity of the surrounding gas. Immanent evaporation and condensation processes of the volatile species are derived using Fick's first law of diffusion, where the gradient in concentration causes a mass flux $I$ away from the particle. When the concentration is expressed in terms of the vapour pressure and temperature using the ideal gas law, the mass flux can be expressed in its general form as:

$$
I(T)=4 \pi r \frac{D M_{\mathrm{v}}}{R}\left[\frac{p_{\mathrm{v}}(T)}{T}-\frac{p_{\mathrm{v}}\left(T_{\infty}\right)}{T_{\infty}}\right]
$$

where $D$ is the diffusion constant in the gas phase, $M_{\mathrm{v}}$ is the molar mass of the evaporating species, $R$ is the ideal gas constant and $p_{\mathrm{v}}$ is the partial pressure of the evaporating species. This is the point where the relative humidity $\varphi$ enters the theory. While the saturation vapour pressure $p_{\mathrm{v} \text {,sat }}$ is a function of temperature $T$ and (ambient) pressure $p$, the partial pressure of water $p_{\mathrm{v}}$ scales linearly with $\varphi$ and $p_{\mathrm{v}, \text { sat }}$. In our experiment we work at constant $p$ and thus the partial pressure of water is simply:

$$
p_{\mathrm{v}}(T)=\varphi \cdot p_{\mathrm{v}, \mathrm{sat}}(T)
$$

Since the transport of energy and mass for particle sizes that we study is partially under kinetic control, an appropriate correction has to be applied. The thermal conductivity $K$ and vapour diffusivity $D$ of the continuum fluxes are modified by the multiplicative transitional correction factors for heat transfer $\beta_{\mathrm{T}}$, and mass transfer $\beta_{\mathrm{M}}$, respectively*. They take the form:

$$
\beta_{i}=\frac{1+\mathrm{Kn}_{\mathrm{i}}}{1+\left(\frac{4}{3 \alpha_{\mathrm{i}}}+0.377\right) \mathrm{Kn}+\frac{4}{3 \alpha_{\mathrm{i}}} \mathrm{Kn}_{\mathrm{i}}^{2}} \quad \text { where } \quad \mathrm{i}=\mathrm{T}, \mathrm{M}
$$

where $\mathrm{Kn}_{\mathrm{i}}$ are the Knudsen numbers $\mathrm{Kn}_{\mathrm{T}}=\lambda_{\mathrm{g}} / r$ and $\mathrm{Kn}_{\mathrm{M}}=\lambda_{\mathrm{v}} / r$ which depend on the particle radius $r$ and the mean free path of the gas molecules (nitrogen) $\lambda_{\mathrm{g}}$ and vapour molecules (water) $\lambda_{\mathrm{v}}$ respectively. The coefficients $\alpha_{\mathrm{i}}$ introduced in eq. 6 are called the thermal accommodation coefficient $\alpha_{\mathrm{T}}$ and the mass accommodation coefficient $\alpha_{\mathrm{M}}$. While $\alpha_{\mathrm{T}}$ is generally assumed to be close to unity, ${ }^{19,75,76,80}$ the value of $\alpha_{\mathrm{M}}$ strongly depends on the system and is in general difficult to measure, as exemplified by the wide spread of values for water on water in the literature. ${ }^{17,19,23-25,59,76,81-83}$

Combining eqs. $1-4$ allows us to solve for the particle temperature $T$. It is oscillating around an average particle temperature $\bar{T}$ :

$$
\bar{T}=\frac{C_{\mathrm{abs}}\left(r, x_{a}\right) I_{0}}{4 \pi r \beta_{\mathrm{T}} K\left(1+f_{\mathrm{M}}\right)}+T_{\infty}
$$

where $f_{\mathrm{M}}$ is defined as the ratio between MF and HF. However, over a complete PA cycle, the net MF of the evaporating species (water) is zero and only the evaporation of the non-volatile species (TEG) enters eq. 7. Since the vapour pressure of TEG is very low, also this steady state mass flux is negligible on the experimental time scale. Ultimately, $f_{\mathrm{M}}$ in eq. 7 is assumed to be zero for our system.

On the timescale of one PA cycle $(250 \mu s)$, the particle temperature is oscillating around $\bar{T}$ with the modulation frequency $\omega$ of the IR-laser, which in turn induces oscillations in $f_{\mathrm{M}}$. The amplitude of the temperature oscillation is denoted with $\Delta T$ and assumed to be symmetric around $\bar{T}$ :

$$
\Delta T=\frac{C_{\mathrm{abs}}\left(r, x_{\mathrm{a}}\right) I_{0}}{4 \pi r \beta_{\mathrm{T}} K\left|1+\delta f_{\mathrm{M}}-i \omega \tau\right|}
$$

${ }^{*}$ Note that there is a minor confusion in the literature, with some authors referencing the value $0.337^{73,75,78}$ instead of 0.377 in the denominator of eq. 6 . Based on the original work of Fuchs and Sutugin, ${ }^{79}$ the correct value is 0.377 . 
where $\delta f_{\mathrm{M}}$ is the oscillation amplitude of $f_{\mathrm{M}}$ and $\tau^{\dagger}$ is the characteristic time constant of the particles thermal inertia, which is given by:

$$
\tau=\frac{r^{2} \rho_{a} c_{\mathrm{p}, \mathrm{a}}}{3 \beta_{\mathrm{T}} K}
$$

where $\rho_{a}$ is the particle density. From our previous work ${ }^{33,34,69}$ we know that $\bar{T}$ increases significantly with particle radius. The equations for $\mathrm{HF}$ and $\mathrm{MF}$ in the traditional model ${ }^{73,74,77}$ start to fail when used for elevated particle temperatures and need to be adapted to compensate for temperature-dependent variables.

In this work we present a refined model for photoacoustic single-particle spectroscopy (PSPS) that accounts for the average particle temperatures $\bar{T}$ to be higher by several Kelvins than the ambient temperature $T_{\infty}$. The critical quantity is the water vapour pressure $p_{\mathrm{v}}(T)$, which, in the basic model, was assumed to scale linearly with temperature starting from the water vapour pressure at ambient temperature, $p_{\mathrm{v}}\left(T_{\infty}\right)$. Mathematically this was realised by a restricted Taylor expansion of the Clausius Clapeyron equation around $T_{\infty}$. In the new model, we build upon this concept, however, we expand the Clausius Clapeyron equation around the average particle temperature $\bar{T}$ in order to reduce the error of the approximation. The equation is then again linearised by using only the first two terms. In this way, the new model only applies the linear scaling of water vapour pressure with temperature to the minor oscillations of $\pm \Delta T$ around $\bar{T}$ :

$$
p_{\mathrm{v}}(T)=p_{\mathrm{v}}(\bar{T}) \mathrm{e}^{\left(\frac{L M_{\mathrm{v}}}{R} \frac{T-\bar{T}}{T \bar{T}}\right)} \approx p_{\mathrm{v}}(\bar{T})\left(1+\frac{L M_{\mathrm{v}}}{R \bar{T}^{2}} \Delta T\right)
$$

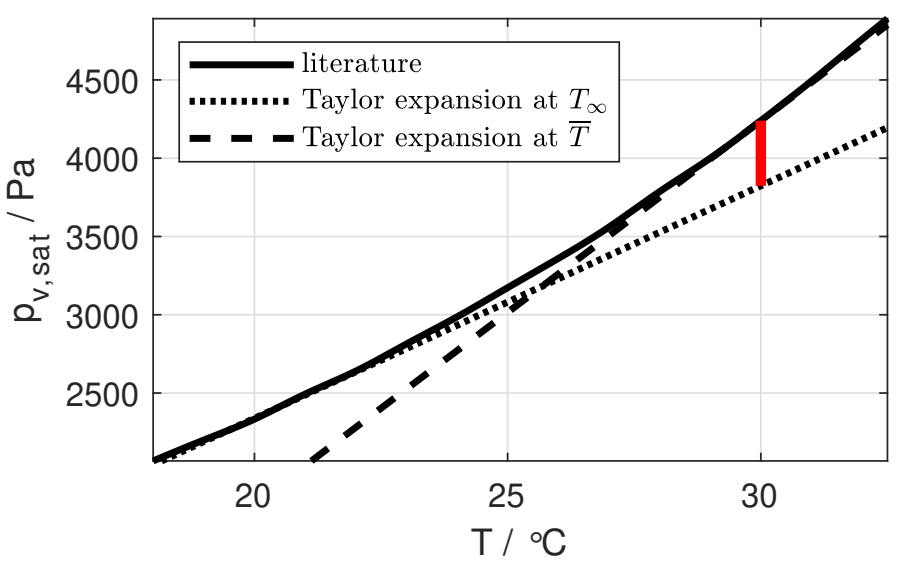

Figure 4. The saturation water vapour pressure against gas temperature from the literature (solid line) [84, table 1.52], using the Taylor expansion around $T_{\infty}$ (dotted line) and Taylor expansion around $\bar{T}$ (dashed line) for $T_{\infty}=20.5^{\circ} C$ and $\bar{T}=30^{\circ} \mathrm{C}$. The red bar indicates the correction in vapour pressure of the new model.

Figure 4 illustrates the correction to the existing model. Calculating the total differential of eq. 4 together with eq. 10 gives the change in mass flux:

$$
\Delta I \approx \frac{\partial I}{\partial T} \Delta T \approx 4 \pi r D \beta_{\mathrm{M}} \frac{M_{\mathrm{v}} p_{\mathrm{v}}(\bar{T})}{R}\left[\frac{L M_{\mathrm{v}}}{R \bar{T}}-1\right] \frac{\Delta T}{(\bar{T}+\Delta T)^{2}}
$$

In principle, the temperature dependence of the heat conductivity of the surrounding gas $K(T)$ should be included, as suggested by Miles et al. ${ }^{59}$ At ambient temperatures and pressures, water is still a trace species

\footnotetext{
${ }^{\dagger}$ Note that in literature slightly different definitions of $\tau$ exist. Since $\beta_{T}$ in eq. 8 is strictly positive, it may be pulled into the modulus brackets where it cancels out in the imaginary term. In that particular formulation of $\Delta T$, $\beta_{T}$ does not enter the definition of $\tau$.
} 
in the surrounding gas phase and contributes less than $1 \%$ to $K$. For this reason it is sufficient to assume a pure nitrogen atmosphere, using:

$$
K(T)=2.45109 \cdot 10^{-4}+9.90738 \cdot 10^{-5} T-4.47915 \cdot 10^{-8} T^{2}
$$

The change in heat flux can be obtained by plugging eq. 12 into eq. 3 and calculating the total differential. Mixed and higher order terms that arise in the total differential are neglected, since they proved to contribute less than $1 \%$ for all attained $\Delta T$, whereas the deviation of eq. 12 itself is given with $\pm 2 \% .{ }^{59}$ Considering that $T=\bar{T}+\Delta T$, the change in the heat flux reduces to:

$$
\Delta Q=4 \pi r \beta_{\mathrm{T}} \frac{\partial\left[K(T)\left(T-T_{\infty}\right)\right]}{\partial T} \Delta T \approx 4 \pi r K(\bar{T}) \beta_{\mathrm{T}} \Delta T
$$

Applying the above to the ratio of the fluxes $f_{\mathrm{M}}$ and its oscillation amplitudes $\delta f_{\mathrm{M}}$, eqs. 11 and 13, yield:

$$
\delta f_{\mathrm{M}}=\frac{\Delta I L}{\Delta Q}=\frac{D \beta_{\mathrm{M}} L M_{\mathrm{v}} p_{\mathrm{v}}(\bar{T})}{R K \beta_{\mathrm{T}}}\left(\frac{L M_{\mathrm{v}}}{R \bar{T}}-1\right) \frac{1}{(\bar{T}+\Delta T)^{2}}
$$

Both heat and mass flux from eqs. 13 and 11 respectively contribute to the overall photoacoustic signal by forming a pressure wave in the surrounding gas with an angular frequency $\omega$. The photoacoustic signal is delayed with respect to the IR laser emission due to the particle's thermal inertia $\tau$. As a result, the measured PA signal $S$ is expressed as a complex quantity with an amplitude $|S|$ and phase $\theta$, which we refer to as the photoacoustic amplitude (PAA) and photoacoustic phase (PAP) respectively:

$$
\begin{gathered}
|S|=\frac{R}{p}\left(\frac{\Delta Q}{M_{\mathrm{g}} c_{\mathrm{p}, \mathrm{g}}}+\frac{\Delta I T_{\infty}}{M_{\mathrm{v}}}\right)=: \text { PAA } \text { and } \\
\theta=\arg \left(\frac{1}{1+\delta f_{\mathrm{M}}-i \omega \tau}\right)=: \text { PAP, }
\end{gathered}
$$

where $M_{\mathrm{g}}$ and $c_{\mathrm{p}, \mathrm{g}}$ are molar mass and specific heat capacity of the surrounding gas $\left(N_{2}\right)$. Note that $\delta f_{\mathrm{M}}$ enters eq. 16 as an essential parameter, while the relative humidity enters eqs. $15-16$ through eq. 5 .

\section{RESULTS}

\subsection{Acoustic properties of the photoacoustic cell as a function of relative humidity}

In order to study the effects of relative humidity on the aerosols' absorption of light using photoacoustic spectroscopy, it is essential to characterise the effects of relative humidity on the acoustic response of the PA cell. Elevated levels of RH change the speed of sound in the gas phase and as a result change the acoustic properties of the acoustic resonator inside the PA cell. In order to investigate these effects, we performed measurements on the background signal in two different PA cells with the same acoustic resonator design. Figure 5 shows the resonance frequencies of the two cells retrieved from the photoacoustic amplitude (PAA) and photoacoustic phase (PAP) as a function of relative humidity. The eigenfrequencies were retrieved from a Lorentzian fit to the PAA data and to the first derivative of the PAP data, as shown in Figure 3. We observe that in general, the eigenfrequencies of the two PA cells differ by $\sim 180 \mathrm{~Hz}$, despite having identical acoustic resonators. This shows that the eigenfrequency of the PA cell is very sensitive to even subtle differences in their design. The trends with relative humidity are more pronounced in cell $\mathrm{B}$ (on the right in Figure 5), where we observe up to $10 \mathrm{~Hz}$ increase of the eigenfrequency when the relative humidity increases from 10 to $95 \%$.

The change of the eigenfrequency with relative humidity can be calculated using the speed of sound in dry and wet nitrogen environments. The eigenfrequency of the open-open resonator is calculated as: ${ }^{85}$

$$
f_{n}=\frac{n c}{2(l+\Delta l)} \quad n=1,2,3, \ldots
$$



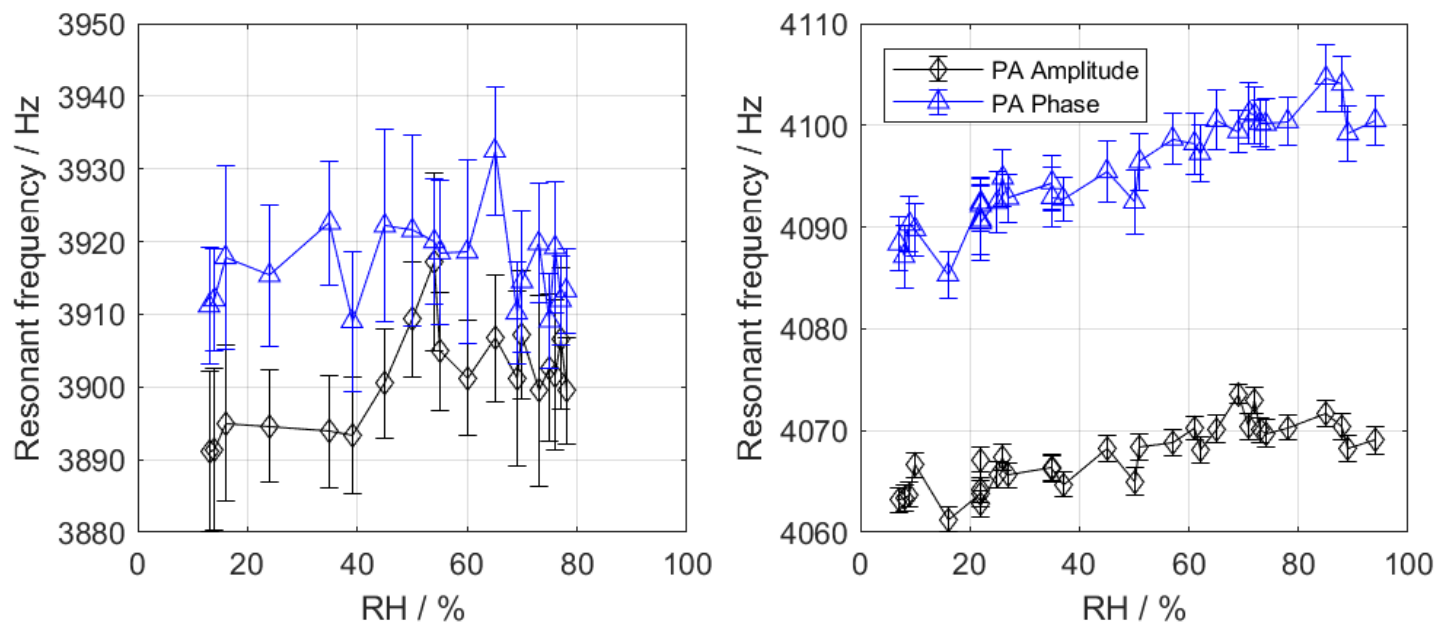

Figure 5. Resonance frequencies of the two PA cells (cell A on the left and cell B on the right) plotted against relative humidity. The resonance frequencies were retrieved from the PA amplitude (black, $\diamond$ ) and phase (blue, $\triangle$ ). The measurements were performed on the background signal.

where $l$ is the length of the acoustic resonator $(40 \mathrm{~mm}), c$ is the speed of sound, $n$ is the excited harmonic and $\Delta l$ is the end correction, which is added to the length of the resonator for each open end. The end correction can be approximated as $\Delta l \cong 0.6 r$, where $r$ is the radius of the acoustic resonator ( $2 \mathrm{~mm}$ in our case). The speed of sound in air at $10 \% \mathrm{RH}$, atmospheric pressure and a temperature of $20^{\circ} \mathrm{C}$ is $\sim 343.49 \mathrm{~ms}^{-1}$ and increases by a factor of $\sim 1.003$ when the relative humidity changes from $10 \%$ to $93 \%{ }^{86}$ From reference 87 , we can approximate the ratio between the speed of sound in nitrogen to air to be 1.034 . Hence, the speed of sound in nitrogen can be approximated to be $355.18 \mathrm{~ms}^{-1}$ at $10 \% \mathrm{RH}$ and $356.24 \mathrm{~ms}^{-1}$ at $93 \%$. Using eq. 17 , we calculate a $12 \mathrm{~Hz}$ shift of the eigenfrequency when the relative humidity changes from $10 \%$ to $93 \%$. This is in agreement with the experimentally retrieved eigenfrequency shift.

Figure 6 shows the PAA and PAP as a function of relative humidity retrieved from the frequency sweeps of the acoustic resonators. The blue trace in Figure 6 represents the PAA and PAP values at the corresponding eigenfrequencies, while the orange trace represents the values retrieved at $4 \mathrm{kHz}$. The data presented was measured on the background signal (no trapped particle). The left hand side corresponds to the PA cell A with the eigenfrequency of $\sim 3900 \mathrm{~Hz}$ (see Figure 5 left), while the right-hand side corresponds to the PA cell $\mathrm{B}$ with the eigenfrequency of $\sim 4080 \mathrm{~Hz}$ (see Figure 5 right). We observe that PAA is smaller at $4 \mathrm{kHz}$ than at the corresponding eigenfrequency, which is to be expected. We also observe a slight increase of PAA with $\mathrm{RH}$, both at $4 \mathrm{kHz}$ and at the eigenfrequency. An important remark is that the trend with $\mathrm{RH}$ is the same at $4 \mathrm{kHz}$ and at the eigenfrequency, suggesting that no $\mathrm{RH}$ biases are introduced by measuring the PA signal at $4 \mathrm{kHz}$ throughout the relative humidity range considered. The trends in PAA are qualitatively similar for both cells.

Regarding PAP, we observe in both cells that there is not a clear difference between the trends of the signal with relative humidity measured at the resonant eigenfrequency (blue trace) or at $4 \mathrm{kHz}$ (orange trace). This is an important confirmation that the PAP measurements performed at different relative humidities are not biased when measured at fixed $4 \mathrm{kHz}$ frequency. However, we observe different overall trends of PAP with $\mathrm{RH}$ between the two PA cells - in cell $\mathrm{B}$, the phase increases with relative humidity, while the trend with $\mathrm{RH}$ in the cell A is not very clear. This is most likely due to the different background signals of the two PA cells, as well as due to the sharpness of the resonance and the effective Q-factor. The PAA in cell B is higher by almost an order of magnitude compared to cell A. This makes the PAP signal in cell B easy to lock in and causes less noise in the data from this cell. As a result, the PAP error bars for cell B are much smaller allowing for the trends with $\mathrm{RH}$ to be visible.

In theory, upon an increase of the eigenfrequency of the acoustic resonator at elevated relative humidity, 

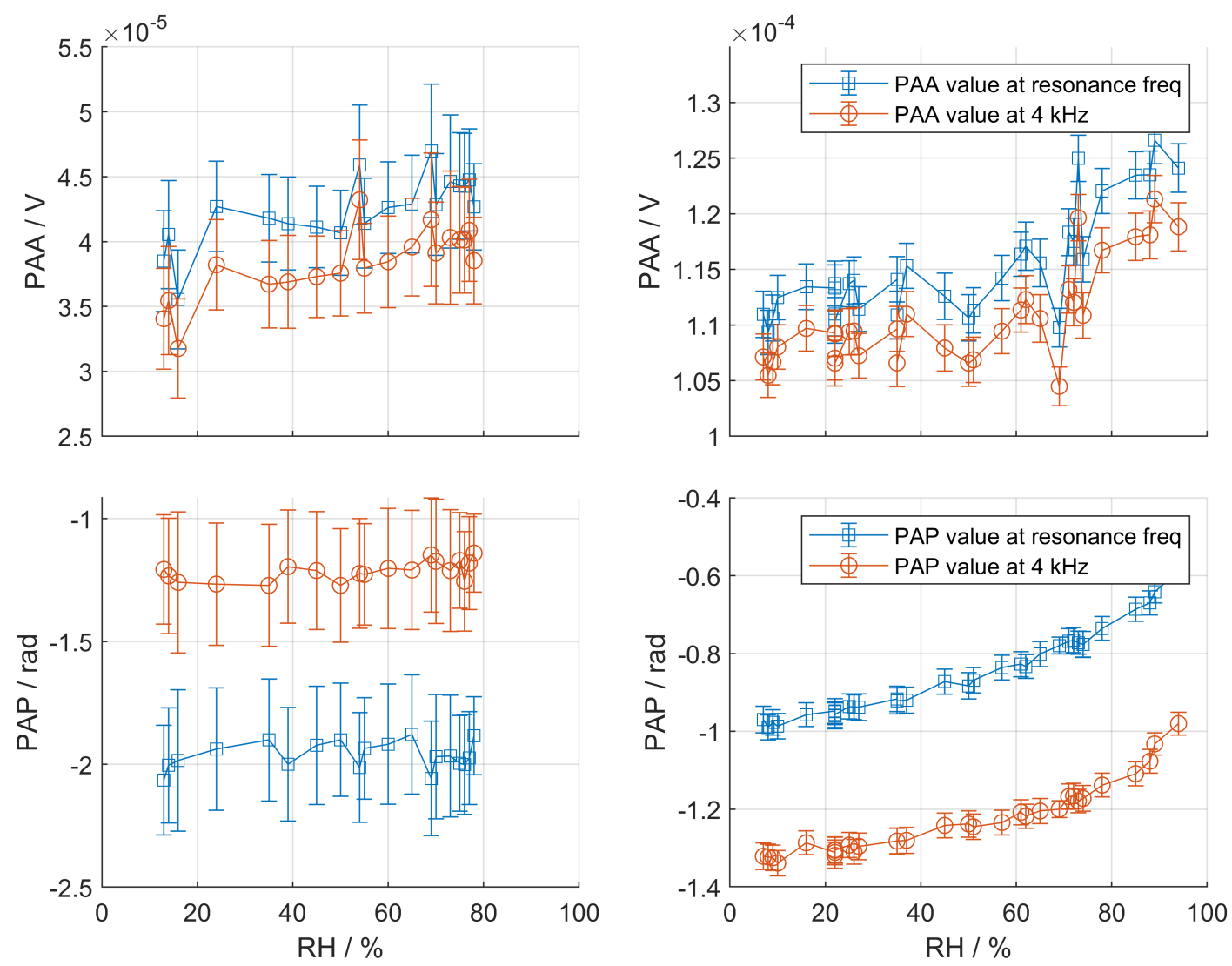

Figure 6. PA amplitude (top) and phase (bottom) values measured in two different cells (cell A on the left and cell $\mathrm{B}$ on the right) at the acoustic eigenfrequency (blue, $\square$ ) and at $4 \mathrm{kHz}$ (orange, $\bigcirc$ ).

the PAP measured at $4 \mathrm{kHz}$ should decrease. This can be seen in Figure 3 left - upon a shift of the blue and orange traces to higher frequencies (horizontal shift to the right), the value of the PAP measured at $4 \mathrm{kHz}$ decreases. Since this is not observed experimentally in Figure 6, we can conclude that the trends observed most likely originate from differing background signals at different $\mathrm{RH}$, rather than from the shift of the eigenfrequency of the resonator.

Overall, we see no pronounced biases associated with the PA measurements at varying relative humidity at the fixed frequency of $4 \mathrm{kHz}$. We observe no differences in trends in the PAA and PAP with relative humidity when measured at the acoustic resonators eigenfrequency or at fixed $4 \mathrm{kHz}$. Furthermore, we do not observe the theorised effect of the eigenfrequency shift with RH on the PAP values, suggesting that this effect is minimal.

\subsection{Refined model}

The newly adapted model presented here is based on the Taylor expansion of the Clausius Clapeyron equation around the average particle temperature as discussed in section 2.2. Using equation 7, we can calculate the particle's average temperature and use available vapour pressure data at these temperatures. ${ }^{84}$ Subsequently, the Taylor expansion is performed over just a few Kelvins, as the particle temperature oscillation $(\Delta T)$ is small. This makes the new model more accurate and more representative of the real experimental conditions. The theoretical results presented in Figure 7 were obtained for exemplary values of the thermal and mass accommodation coefficient and $T_{\infty}=20.5^{\circ} \mathrm{C}$. For $\alpha_{\mathrm{T}}$ the value of 0.97 was selected. ${ }^{25,77,88} \mathrm{We}$ point out that the corrections to the heat flux have only a small influence $(<5 \%)$ on the simulation results. Regarding the mass accommodation coefficient, a constant value of $\alpha_{\mathrm{M}}=0.1$ was chosen, which approximates the mass accommodation coefficient values of water on organics. ${ }^{33,67,69}$ 

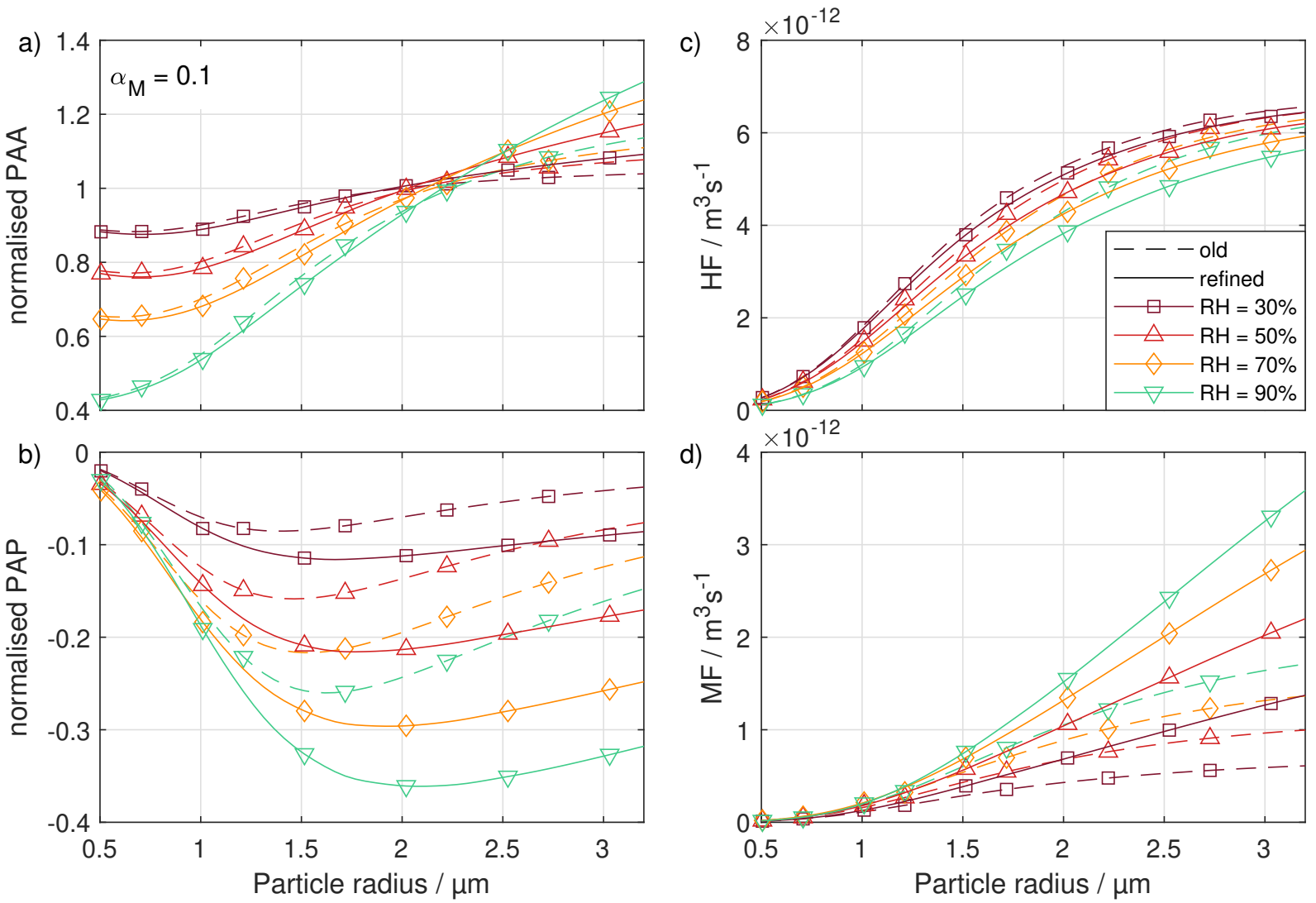

Figure 7. Comparison between the new refined model (solid lines) and the old model (dashed lines) for relative humidities $30 \%$ (brown, $\square$ ), $50 \%$ (red, $\triangle$ ), $70 \%$ (orange, $\diamond$ ), $90 \%$ (green, $\nabla$ ). The following signals were simulated: (a) photoacoustic amplitude (PAA); (b) photoacoustic phase (PAP); (c) heat flux (HF) and (d) mass flux (MF).

Figure 7 shows a comparison between the old and new refined model. The PAA and PAP signals are normalised to $\varphi=11 \%$ of the respective model, which is the lowest accessible relative humidity of our experimental set-up and is assumed to be the dry case. At small particle radii $(0.5-1.0 \mu \mathrm{m})$, the old and the refined model mostly overlap, since the particle's temperature is not greatly elevated. ${ }^{33}$ At bigger particle sizes $(1.0-3.0 \mu \mathrm{m})$ we observe deviations in all four simulated quantities.

Both PAA (Figure 7 a) and PAP (Figure 7 b) simulations show a bigger dependence on RH using the new model throughout the entire size range considered. The heat and mass flux (Figure $7 \mathrm{c}$ and $\mathrm{d}$ ) follow the same trend, with the mass flux contribution increasing substantially in the new model. Overall, the trends of PAA, PAP, HF and MF with particle size are qualitatively similar to the old model, but the dependence on $\mathrm{RH}$ increases. In our previous work we used the $\mathrm{RH}$-dependence of PAA and PAP to retrieve the mass accommodation coefficients. ${ }^{33,69,70}$ Hence, we can use the refined model to retrieve new values of the mass accommodation coefficients in order to evaluate its performance.

\subsection{Mass accommodation coefficient}

The mass accommodation coefficients are retrieved for the system of water on tetraethylene glycol aerosols using experimental data that was presented elsewhere ${ }^{33,34,69}$ and applying the refined model, which is presented in this paper (section 2.2). We used tetraethylene glycol (TEG) aerosol particles as a proxy for organics. Organic aerosols constitute up to $80 \%$ of all the particulate matter in the atmosphere, ${ }^{80,89-91}$ making studies on such systems of high atmospheric relevance. Furthermore, organic aerosols are routinely used for drug delivery to the lungs, but their water uptake in the human airways significantly influences the efficiency of the drug delivery. ${ }^{92-94}$ The experimental data comprises photoacoustic measurements of over 390 particles that 
were optically trapped in the photoacoustic cell at different levels of relative humidity. The refined model lets us simulate our system closer to real experimental conditions, yet the trends and general phenomena discussed in our previous work are not altered. ${ }^{33,34}$ We use the new refined model to retrieve the mass accommodation coefficient $\left(\alpha_{\mathrm{M}}\right)$ from the photoacoustic amplitude and phase, which is shown in Figure 8. Details concerning the $\alpha_{\mathrm{M}}$ retrieval can be found in the Supporting Information of ref. 69 .
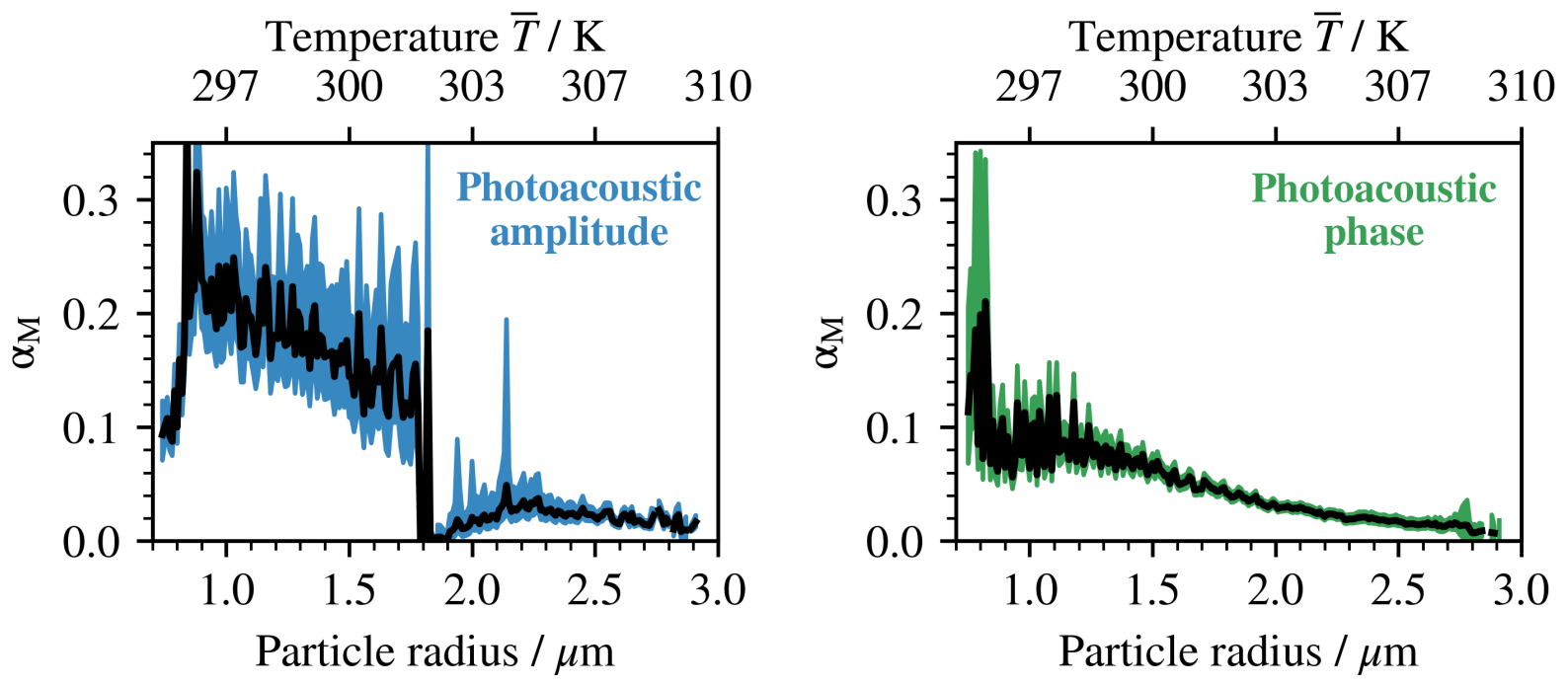

Figure 8. The mass accommodation coefficient $\left(\alpha_{\mathrm{M}}\right)$ retrieved from photoacoustic amplitude (left) and photoacoustic phase (right).

Compared to our previous work, ${ }^{69}$ we observe a better match among the $\alpha_{\mathrm{M}}$ values retrieved from the two independent techniques and we obtain smaller and more consistent error bars. The reduced deviations in the $\alpha_{\mathrm{M}}$ values directly illustrate a better match of the theory and experimental data. The mass accommodation coefficient retrieved from the photoacoustic phase (Figure 8 right) shows much smaller error bars than the photoacoustic amplitude retrieval (Figure 8 left). This can be rationalised by considering the relative spacing of the PAP curves at different relative humidity (Figure $7 \mathrm{~b}$ ), which is significantly larger than that of the PAA curves (Figure 7 a). Furthermore, through comparison of the solid and dashed lines in Figure $7 \mathrm{~b}$, we see a larger relative spread of the individual PAP curves with RH compared to the previous model, which greatly benefits the fit accuracy when using the photoacoustic phase. The major issue of the $\alpha_{\mathrm{M}}$ retrieval from the PAA data remains the size region (2.1-2.6 $\mu \mathrm{m}$ for the example values in Figure 7 a) where the individual PAA curves at specific RH overlap. In this size range, the trend of the PAA signal with RH cannot be fitted reliably. The photoacoustic phase data does not show this behaviour as the individual PAP curves do not cross in the size range (Figure $7 \mathrm{~b}$ ).

Both techniques yield largely overlapping values of the mass accommodation coefficients with the same trends. We observe decreasing values of $\alpha_{\mathrm{M}}$ with particle radius, which is due to elevated particle temperatures at large radii. This trend has been discussed in detail in Ref. 69. The temperature dependence of the mass accommodation coefficient can be rationalised in terms of kinetic rates of solvation and desorption of the surface adsorbed species, as proposed by Nathanson et al. ${ }^{95}$ A thorough understanding of the temperaturedependence of $\alpha_{\mathrm{M}}$ is crucial for example in climate modelling, where water uptake by aerosol particles differs at different altitudes in the troposphere due to a significant change in temperature.

\section{CONCLUSION}

In this contribution, we have discussed the influence of relative humidity on photoacoustic measurements performed on single aerosol particles. The particles were optically trapped using counter-propagating tweezers. We evaluated the effect of the change of speed of sound at different relative humidities on the eigenfrequency 
of the acoustic resonators used in the photoacoustic cells. We have found a shift of up to $10 \mathrm{~Hz}$ in the eigenfrequency when the relative humidity changes from $10 \%$ to $93 \%$. Furthermore, we have presented a refined model that addresses elevated particle temperatures in the photoacoustic measurements. With this new model, we retrieved the mass accommodation coefficients of water on organic aerosols, using our previously presented data. ${ }^{33,34,69}$ We measured two independent signals - photoacoustic amplitude and phase - that were used for the mass accommodation coefficient retrieval. Compared to the old model that we applied in the past, we observe more consistent mass accommodation coefficient retrievals among the two independent techniques and we obtain smaller and more consistent error bars. Overall, we can conclude that the new refined model, that builds upon the vapour pressure expansion centred around $\bar{T}$, is a significant improvement.

\section{ACKNOWLEDGMENTS}

The work presented here was financially supported by the Swiss National Science Foundation (grants no. 200021E_177479 and 200020_172472) and ETH Research Grant ETH-42 18-1. The authors thank David Stapfer and Markus Steger from the Laboratory of Physical Chemistry ETHZ for their technical help. The authors thank Prof. Christoph Haisch and Emilio Ambra for useful discussions.

\section{REFERENCES}

[1] Fan, J., Wang, Y., Rosenfeld, D., and Liu, X., "Review of aerosol-cloud interactions: Mechanisms, significance, and challenges," J. Atmos. Sci. 73(11), 4221-4252 (2016).

[2] Seinfeld, J. H., Bretherton, C., Carslaw, K. S., Coe, H., DeMott, P. J., Dunlea, E. J., Feingold, G., Ghan, S., Guenther, A. B., Kahn, R., Kraucunas, I., Kreidenweis, S. M., Molina, M. J., Nenes, A., Penner, J. E., Prather, K. A., Ramanathan, V., Ramaswamy, V., Rasch, P. J., Ravishankara, A. R., Rosenfeld, D., Stephens, G., and Wood, R., "Improving our fundamental understanding of the role of aerosol-cloud interactions in the climate system," Proc. Natl. Acad. Sci. U. S. A. 113(21), 5781-5790 (2016).

[3] Fanourgakis, G. S., Kanakidou, M., Nenes, A., Bauer, S. E., Bergman, T., Carslaw, K. S., Grini, A., Hamilton, D. S., Johnson, J. S., Karydis, V. A., Kirkevåg, A., Kodros, J. K., Lohmann, U., Luo, G., Makkonen, R., Matsui, H., Neubauer, D., Pierce, J. R., Schmale, J., Stier, P., Tsigaridis, K., van Noije, T., Wang, H., Watson-Parris, D., Westervelt, D. M., Yang, Y., Yoshioka, M., Daskalakis, N., Decesari, S., Gysel-Beer, M., Kalivitis, N., Liu, X., Mahowald, N. M., Myriokefalitakis, S., Schrödner, R., Sfakianaki, M., Tsimpidi, A. P., Wu, M., and Yu, F., "Evaluation of global simulations of aerosol particle and cloud condensation nuclei number, with implications for cloud droplet formation," Atmos. Chem. Phys. 19, 8591-8617 (jul 2019).

[4] Wilcox, L. J., Highwood, E. J., Booth, B. B. B., and Carslaw, K. S., "Quantifying sources of inter-model diversity in the cloud albedo effect," Geophys. Res. Lett. 42(5), 1568-1575 (2015).

[5] Nordling, K., Korhonen, H., Räisänen, P., Alper, M. E., Uotila, P., O'Donnell, D., and Merikanto, J., "Role of climate model dynamics in estimated climate responses to anthropogenic aerosols," Atmos. Chem. Phys. 19, 9969-9987 (Aug. 2019).

[6] Janssen, N. A. H., Gerlofs-Nijland, M. E., Lanki, T., Salonen, R. O., Cassee, F., Hoek, G., Fischer, P., Brunekreef, B., and Krzyzanowski, M., "Health effects of black carbon," tech. rep., Scherfigsvej 8, DK-2100 Copenhagen Ø, Denmark (2012).

[7] Silverman, D. T., Samanic, C. M., Lubin, J. H., Blair, A. E., Stewart, P. A., Vermeulen, R., Coble, J. B., Rothman, N., Schleiff, P. L., Travis, W. D., Ziegler, R. G., Wacholder, S., and Attfield, M. D., "The Diesel Exhaust in Miners Study: A Nested Case Control Study of Lung Cancer and Diesel Exhaust," JNCI: Journal of the National Cancer Institute 104, 855-868 (06 2012).

[8] Cao, J., Eichler, C. M. A., Wu, Y., and Little, J. C., "Dynamic method to measure partition coefficient and mass accommodation coefficient for gas-particle interaction of phthalates," Aerosol Science and Technology 53, 1158-1171 (June 2019).

[9] U.S. Environmental Protection Agency, [Integrated Science Assessment (ISA) for Particulate Matter (Final Report, 2019)], vol. EPA/600/R-19/188, Center for Public Health and Environmental Assessment, Washington, DC (Dec. 2019). 
[10] Bzdek, B. R. and Reid, J. P., "Perspective: Aerosol microphysics: From molecules to the chemical physics of aerosols," J. Chem. Phys 147, 220901 (dec 2017).

[11] Krieger, U. K., Marcolli, C., and Reid, J. P., "Exploring the complexity of aerosol particle properties and processes using single particle techniques," Chem. Soc. Rev. 41(19), 6631 (2012).

[12] Vehkamäki, H. and Riipinen, I., "Thermodynamics and kinetics of atmospheric aerosol particle formation and growth," Chem. Soc. Rev. 41(15), 5160 (2012).

[13] Rosenfeld, D., "Suppression of rain and snow by urban and industrial air pollution," Science 287, 17931796 (mar 2000).

[14] Chuang, P. Y., Charlson, R. J., and Seinfeld, J. H., "Kinetic limitations on droplet formation in clouds," Nature 390, 594-596 (dec 1997).

[15] Davis, E., "A history and state-of-the-art of accommodation coefficients," Atmos. Res. 82, 561-578 (dec 2006).

[16] Kolb, C. E., Cox, R. A., Abbatt, J. P. D., Ammann, M., Davis, E. J., Donaldson, D. J., Garrett, B. C., George, C., Griffiths, P. T., Hanson, D. R., Kulmala, M., McFiggans, G., Pöschl, U., Riipinen, I., Rossi, M. J., Rudich, Y., Wagner, P. E., Winkler, P. M., Worsnop, D. R., and O' Dowd, C. D., "An overview of current issues in the uptake of atmospheric trace gases by aerosols and clouds," Atmos. Chem. Phys. 10(21), 10561-10605 (2010).

[17] Davidovits, P., Kolb, C. E., Williams, L. R., Jayne, J. T., and Worsnop, D. R., "Update 1 of: Mass accommodation and chemical reactions at gas-liquid interfaces," Chem. Rev. 111 (Apr. 2011).

[18] Maxwell, J. C., "On the dynamical theory of gases," Phil. Trans. Royal Society 1, 49-88 (1859).

[19] Li, Y. Q., Davidovits, P., Kolb, C. E., and Worsnop, D. R., "Mass and thermal accommodation coefficients of $\mathrm{h} 2 \mathrm{o}(\mathrm{g})$ on liquid water as a function of temperature," J. Phys. Chem. A 105, 10627-10634 (Nov. 2001).

[20] Kreidenweis, S. M., "Modification of aerosol mass and size distribution due to aqueous-phase SO2oxidation in clouds: Comparisons of several models," J. Geophys. Res. 108(D7) (2003).

[21] Longest, P. W. and Hindle, M., "Condensational growth of combination drug-excipient submicrometer particles for targeted high efficiency pulmonary delivery: Comparison of CFD predictions with experimental results," Pharm. Res. 29, 707-721 (sep 2011).

[22] Longest, P. W., Tian, G., Li, X., Son, Y.-J., and Hindle, M., "Performance of combination drug and hygroscopic excipient submicrometer particles from a softmist inhaler in a characteristic model of the airways," Ann. Biomed. Eng. 40, 2596-2610 (Dec 2012).

[23] Davidovits, P., Worsnop, D. R., Jayne, J. T., Kolb, C. E., Winkler, P., Vrtala, A., Wagner, P. E., Kulmala, M., Lehtinen, K. E. J., Vesala, T., and Mozurkewich, M., "Mass accommodation coefficient of water vapor on liquid water," Geophys. Res. Lett. 31 (May 2004).

[24] Eames, I., Marr, N., and Sabir, H., "The evaporation coefficient of water: a review," Int. J. Heat Mass Transfer 40(12), 2963 - 2973 (1997).

[25] Winkler, P. M., Vrtala, A., Rudolf, R., Wagner, P. E., Riipinen, I., Vesala, T., Lehtinen, K. E. J., Viisanen, Y., and Kulmala, M., "Condensation of water vapor: Experimental determination of mass and thermal accommodation coefficients," J. Geophys. Res.: Atmos. 111(D19), D19202 (2006).

[26] Arnott, W. P., Walker, J. W., Moosmüller, H., Elleman, R. A., Jonsson, H. H., Buzorius, G., Conant, W. C., Flagan, R. C., and Seinfeld, J. H., "Photoacoustic insight for aerosol light absorption aloft from meteorological aircraft and comparison with particle soot absorption photometer measurements: DOE southern great plains climate research facility and the coastal stratocumulus imposed perturbation experiments," J. Geophys. Res.: Atmos. 111(D5) (2006).

[27] Arnott, W. P., Moosmüller, H., Sheridan, P. J., Ogren, J. A., Raspet, R., Slaton, W. V., Hand, J. L., Kreidenweis, S. M., and Collett, J. L., "Photoacoustic and filter-based ambient aerosol light absorption measurements: Instrument comparisons and the role of relative humidity," J. Geophys. Res.: Atmos. 108(D1), D1, 4034 (2003).

[28] Lack, D. A., Richardson, M. S., Law, D., Langridge, J. M., Cappa, C. D., McLaughlin, R. J., and Murphy, D. M., "Aircraft instrument for comprehensive characterization of aerosol optical properties, part 2: Black and brown carbon absorption and absorption enhancement measured with photo acoustic spectroscopy," Aerosol Sci. Technol. 46, 555-568 (May 2012). 
[29] Lewis, K. A., Arnott, W. P., Moosmüller, H., Chakrabarty, R. K., Carrico, C. M., Kreidenweis, S. M., Day, D. E., Malm, W. C., Laskin, A., Jimenez, J. L., Ulbrich, I. M., Huffman, J. A., Onasch, T. B., Trimborn, A., Liu, L., and Mishchenko, M. I., "Reduction in biomass burning aerosol light absorption upon humidification: roles of inorganically-induced hygroscopicity, particle collapse, and photoacoustic heat and mass transfer," Atmos. Chem. Phys. 9(22), 8949-8966 (2009).

[30] Mason, B., Wagner, N. L., Adler, G., Andrews, E., Brock, C. A., Gordon, T. D., Lack, D. A., Perring, A. E., Richardson, M. S., Schwarz, J. P., Shook, M. A., Thornhill, K. L., Ziemba, L. D., and Murphy, D. M., "An intercomparison of aerosol absorption measurements conducted during the seac4rs campaign," Aerosol Sci. Technol. 52(9), 1012-1027 (2018).

[31] Davies, N. W., Fox, C., Szpek, K., Cotterell, M. I., Taylor, J. W., Allan, J. D., Williams, P. I., Trembath, J., Haywood, J. M., and Langridge, J. M., "Evaluating biases in filter-based aerosol absorption measurements using photoacoustic spectroscopy," Atmos. Meas. Tech. 12, 3417-3434 (jun 2019).

[32] Cremer, J. W., Thaler, K. M., Haisch, C., and Signorell, R., "Photoacoustics of single laser-trapped nanodroplets for the direct observation of nanofocusing in aerosol photokinetics," Nat. Commun. 7, 10941 (2016).

[33] Diveky, M. E., Roy, S., Cremer, J. W., David, G., and Signorell, R., "Assessing relative humidity dependent photoacoustics to retrieve mass accommodation coefficients of single optically trapped aerosol particles," Phys. Chem. Chem. Phys. 21, 4721-4731 (2019).

[34] Diveky, M. E., Roy, S., David, G., Cremer, J. W., and Signorell, R., "Fundamental investigation of photoacoustic signal generation from single aerosol particles at varying relative humidity," Photoacoustics 18, 100170 (jun 2020).

[35] Langridge, J. M., Richardson, M. S., Lack, D. A., Brock, C. A., and Murphy, D. M., "Limitations of the photoacoustic technique for aerosol absorption measurement at high relative humidity," Aerosol Sci. Technol. 47(11), 1163-1173 (2013).

[36] Ajtai, T., Filep, Á., Schnaiter, M., Linke, C., Vragel, M., Bozóki, Z., Szabó, G., and Leisner, T., "A novel multi-wavelength photoacoustic spectrometer for the measurement of the UV-vis-NIR spectral absorption coefficient of atmospheric aerosols," J. Aerosol Sci. 41, 1020-1029 (nov 2010).

[37] Haisch, C., Menzenbach, P., Bladt, H., and Niessner, R., "A wide spectral range photoacoustic aerosol absorption spectrometer," Anal. Chem. 84, 8941-8945 (Nov. 2012).

[38] Haisch, C., "Photoacoustic spectroscopy for analytical measurements," Meas. Sci. Technol. 23(1), 012001 (2012).

[39] Patimisco, P., Scamarcio, G., Tittel, F. K., and Spagnolo, V., "Quartz-enhanced photoacoustic spectroscopy: A review," Sensors 14(4), 6165-6206 (2014).

[40] Breitegger, P., Schriefl, M. A., Nishida, R. T., Hochgreb, S., and Bergmann, A., "Soot mass concentration sensor using quartz-enhanced photoacoustic spectroscopy," Aerosol Sci. Technol. 53, 971-975 (jul 2019).

[41] Zheng, H., Liu, Y., Lin, H., Liu, B., Gu, X., Li, D., Huang, B., Wu, Y., Dong, L., Zhu, W., Tang, J., Guan, H., Lu, H., Zhong, Y., Fang, J., Luo, Y., Zhang, J., Yu, J., Chen, Z., and Tittel, F. K., "Quartz-enhanced photoacoustic spectroscopy employing pilot line manufactured custom tuning forks," Photoacoustics 17, 100158 (mar 2020).

[42] Hu, L., Zheng, C., Zhang, M., Yao, D., Zheng, J., Zhang, Y., Wang, Y., and Tittel, F. K., "Quartzenhanced photoacoustic spectroscopic methane sensor system using a quartz tuning fork-embedded, double-pass and off-beam configuration," Photoacoustics 18, 100174 (jun 2020).

[43] Breitegger, P., Schweighofer, B., Wegleiter, H., Knoll, M., Lang, B., and Bergmann, A., "Towards low-cost QEPAS sensors for nitrogen dioxide detection," Photoacoustics 18, 100169 (jun 2020).

[44] Nirmal, M., Dabbousi, B. O., Bawendi, M. G., Macklin, J. J., Trautman, J. K., Harris, T. D., and Brus, L. E., "Fluorescence intermittency in single cadmium selenide nanocrystals," Nature 383, 802-804 (oct 1996).

[45] Miles, R., Carruthers, A., and Reid, J., "Novel optical techniques for measurements of light extinction, scattering and absorption by single aerosol particles," Laser Photonics Rev. 5, 534-552 (mar 2011).

[46] Cotterell, M. I., Mason, B. J., Carruthers, A. E., Walker, J. S., Orr-Ewing, A. J., and Reid, J. P., "Measurements of the evaporation and hygroscopic response of single fine-mode aerosol particles using a bessel beam optical trap," Phys. Chem. Chem. Phys. 16(5), 2118-2128 (2014). 
[47] Gong, Z., Pan, Y.-L., Videen, G., and Wang, C., "Optical trapping and manipulation of single particles in air: Principles, technical details, and applications," J. Quant. Spectrosc. Radiat. Transfer 214, $94-$ 119 (2018).

[48] David, G., Esat, K., Hartweg, S., Cremer, J., Chasovskikh, E., and Signorell, R., "Stability of aerosol droplets in Bessel beam optical traps under constant and pulsed external forces," J. Chem. Phys. 142(15), 154506 (2015).

[49] Thanopulos, I., Luckhaus, D., Preston, T. C., and Signorell, R., "Dynamics of submicron aerosol droplets in a robust optical trap formed by multiple bessel beams," J. Appl. Phys. 115, 154304 (apr 2014).

[50] Rkiouak, L., Tang, M. J., Camp, J. C. J., McGregor, J., Watson, I. M., Cox, R. A., Kalberer, M., Ward, A. D., and Pope, F. D., "Optical trapping and raman spectroscopy of solid particles," Phys. Chem. Chem. Phys. 16(23), 11426-11434 (2014).

[51] Kraikivski, P., Pouligny, B., and Dimova, R., "Implementing both short- and long-working-distance optical trappings into a commercial microscope," Rev. Sci. Instrum. 77, 113703 (nov 2006).

[52] David, G., Reich, O., Divéky, M. E., Roy, S., Parmentier, E. A., Cremer, J. W., Esat, K., and Signorell, R., "Characterization and control of droplets optically trapped in air," in [Optical Trapping and Optical Micromanipulation XVI], Dholakia, K. and Spalding, G. C., eds., SPIE (sep 2019).

[53] David, G., Esat, K., Ritsch, I., and Signorell, R., "Ultraviolet broadband light scattering for opticallytrapped submicron-sized aerosol particles," Phys. Chem. Chem. Phys. 18(7), 5477-5485 (2016).

[54] Bain, A. and Preston, T. C., "Mie scattering from strongly absorbing airborne particles in a photophoretic trap," J. Appl. Phys. 125, 093101 (mar 2019).

[55] Willoughby, R. E., Cotterell, M. I., Lin, H., Orr-Ewing, A. J., and Reid, J. P., "Measurements of the imaginary component of the refractive index of weakly absorbing single aerosol particles," J. Phys. Chem. A 121(30), 5700-5710 (2017). PMID: 28691810.

[56] Shepherd, R. H., King, M. D., Marks, A. A., Brough, N., and Ward, A. D., "Determination of the refractive index of insoluble organic extracts from atmospheric aerosol over the visible wavelength range using optical tweezers," Atmos. Chem. Phys. 18, 5235-5252 (apr 2018).

[57] Rafferty, A. and Preston, T. C., "Measuring the size and complex refractive index of an aqueous aerosol particle using electromagnetic heating and cavity-enhanced raman scattering," Phys. Chem. Chem. Phys. 20(25), 17038-17047 (2018).

[58] Davidson, N. M., Gallimore, P. J., Bateman, B., Ward, A. D., Botchway, S. W., Kalberer, M., Kuimova, M. K., and Pope, F. D., "Measurement of the fluorescence lifetime of GFP in high refractive index levitated droplets using FLIM," Phys. Chem. Chem. Phys. 22(26), 14704-14711 (2020).

[59] Miles, R. E. H., Reid, J. P., and Riipinen, I., "Comparison of approaches for measuring the mass accommodation coefficient for the condensation of water and sensitivities to uncertainties in thermophysical properties," J. Phys. Chem. A 116, 10810-10825 (Nov. 2012).

[60] Davidson, N., Tong, H.-J., Kalberer, M., Seville, P., Ward, A., Kuimova, M., and Pope, F., "Measurement of the raman spectra and hygroscopicity of four pharmaceutical aerosols as they travel from pressurised metered dose inhalers (pMDI) to a model lung," Int. J. Pharm. 520, 59-69 (mar 2017).

[61] Frossard, A. A., Li, W., Gérard, V., Nozière, B., and Cohen, R. C., "Influence of surfactants on growth of individual aqueous coarse mode aerosol particles," Aerosol Sci. Technol. 52, 459-469 (jan 2018).

[62] David, G., Parmentier, E. A., Taurino, I., and Signorell, R., "Tracing the composition of single e-cigarette aerosol droplets in situ by laser-trapping and raman scattering," Sci. Rep. 10 (may 2020).

[63] Fitzgerald, C., Hosny, N. A., Tong, H., Seville, P. C., Gallimore, P. J., Davidson, N. M., Athanasiadis, A., Botchway, S. W., Ward, A. D., Kalberer, M., Kuimova, M. K., and Pope, F. D., "Fluorescence lifetime imaging of optically levitated aerosol: a technique to quantitatively map the viscosity of suspended aerosol particles," Phys. Chem. Chem. Phys. 18(31), 21710-21719 (2016).

[64] Bzdek, B. R., Power, R. M., Simpson, S. H., Reid, J. P., and Royall, C. P., "Precise, contactless measurements of the surface tension of picolitre aerosol droplets," Chem. Sci. 7(1), 274-285 (2016).

[65] Cremer, J. W., Covert, P. A., Parmentier, E. A., and Signorell, R., "Direct Measurement of Photoacoustic Signal Sensitivity to Aerosol Particle Size," J. Phys. Chem. Lett. 8(14), 3398-3403 (2017). 
[66] Covert, P. A., Cremer, J. W., and Signorell, R., "Photoacoustic absorption spectroscopy of single optically trapped aerosol droplets," in [Proc. SPIE, Optical Trapping and Optical Micromanipulation XIV, 1034729], SPIE (2017).

[67] Diveky, M. E., Roy, S., Cremer, J. W., David, G., and Signorell, R., "Correction: Assessing relative humidity dependent photoacoustics to retrieve mass accommodation coefficients of single optically trapped aerosol particles," Phys. Chem. Chem. Phys. 22(27), 15770-15771 (2020).

[68] Lack, D. A., Quinn, P. K., Massoli, P., Bates, T. S., Coffman, D., Covert, D. S., Sierau, B., Tucker, S., Baynard, T., Lovejoy, E., Murphy, D. M., and Ravishankara, A. R., "Relative humidity dependence of light absorption by mineral dust after long-range atmospheric transport from the sahara," Geophys. Res. Lett. 36(24), L24805 (2009).

[69] Roy, S., Diveky, M. E., and Signorell, R., "Mass accommodation coefficients of water on organics from complementary photoacoustic and light scattering measurements on laser-trapped droplets," J. Phys. Chem. C 124, 2481-2489 (Jan. 2020).

[70] Roy, S., Diveky, M. E., and Signorell, R., "Correction to " mass accommodation coefficients of water on organics from complementary photoacoustic and light scattering measurements on laser-trapped droplets"," J. Phys. Chem. C 124, 17848-17849 (aug 2020).

[71] Cotterell, M. I., Ward, G. P., Hibbins, A. P., Haywood, J. M., Wilson, A., and Langridge, J. M., "Optimizing the performance of aerosol photoacoustic cells using a finite element model. part 1: Method validation and application to single-resonator multipass cells," Aerosol Sci. Technol. 0(0), 1-21 (2019).

[72] Cotterell, M. I., Ward, G. P., Hibbins, A. P., Wilson, A., Haywood, J. M., and Langridge, J. M., "Optimizing the performance of aerosol photoacoustic cells using a finite element model. part 2: Application to a two-resonator cell," Aerosol Sci. Technol. 53, 1128-1148 (sep 2019).

[73] Kulmala, M., Vesala, T., and Wagner, P., "An analytical expression for the rate of binary condensational particle growth: Comparison with numerical results," J. Aerosol Sci. 23, 133 - 136 (1992). Proceedings of the 1992 European Aerosol Conference.

[74] Kulmala, M., "Condensational growth and evaporation in the transition regime," Aerosol Sci. Technol. 19, 381-388 (jan 1993).

[75] Riipinen, I., Svenningsson, B., Bilde, M., Gaman, A., Lehtinen, K., and Kulmala, M., "A method for determining thermophysical properties of organic material in aqueous solutions: Succinic acid," Atmos. Res. 82(3), 579 - 590 (2006). 16th International Conference on Nucleation and Atmospheric Aerosols.

[76] Winkler, P. M., Vrtala, A., Wagner, P. E., Kulmala, M., Lehtinen, K. E. J., and Vesala, T., "Mass and thermal accommodation during gas-liquid condensation of water," Phys. Rev. Lett. 93, 075701 (Aug 2004).

[77] Murphy, D. M., "The effect of water evaporation on photoacoustic signals in transition and molecular flow," Aerosol Sci. Technol. 43(4), 356-363 (2009).

[78] Kulmala, M. and Wagner, P. E., "Mass accommodation and uptake coefficients - a quantitative comparison," J. Aerosol Sci. 32, 833-841 (July 2001).

[79] Fuchs, N. A. and Sutugin, A. G., "Highly dispersed aerosols," in [Topics in Current Aerosol Research], Hidy, G. M. and Brock, J. R., eds., International Reviews in Aerosol Physics and Chemistry 2, ch. Properties of HDAs, 29-37, Pergamon (June 1971).

[80] Murphy, D. M., Cziczo, D. J., Froyd, K. D., Hudson, P. K., Matthew, B. M., Middlebrook, A. M., Peltier, R. E., Sullivan, A., Thomson, D. S., and Weber, R. J., "Single-particle mass spectrometry of tropospheric aerosol particles," J. Geophys. Res.: Atmos. 111(D23) (2006).

[81] Mozurkewich, M., "Aerosol growth and the condensation coefficient for water: A review," Aerosol Sci. Technol. 5, 223-236 (jan 1986).

[82] Marek, R. and Straub, J., "Analysis of the evaporation coefficient and the condensation coefficient of water," Int. J. Heat Mass Transfer 44(1), 39 - 53 (2001).

[83] Zientara, M., Jakubczyk, D., Kolwas, K., and Kolwas, M., "Temperature dependence of the evaporation coefficient of water in air and nitrogen under atmospheric pressure: Study in water droplets," J. Phys. Chem. A 112, 5152-5158 (June 2008). 
[84] Lange, N. A., [Langeś Handbook of Chemistry], McGraw-Hill Education, New York, seventeenth edition ed. (2017).

[85] Miklós, A., Hess, P., and Bozóki, Z., "Application of acoustic resonators in photoacoustic trace gas analysis and metrology," Rev. Sci. Instrum. 72, 1937-1955 (apr 2001).

[86] Cramer, O., "The variation of the specific heat ratio and the speed of sound in air with temperature, pressure, humidity, and CO2 concentration," The Journal of the Acoustical Society of America 93, 25102516 (may 1993).

[87] Meier, K. and Kabelac, S., "Speed-of-sound measurements in compressed nitrogen and dry air," Journal of Chemical \& Engineering Data 61, 3941-3951 (oct 2016).

[88] Hołyst, R., Litniewski, M., Jakubczyk, D., Kolwas, K., Kolwas, M., Kowalski, K., Migacz, S., Palesa, S., and Zientara, M., "Evaporation of freely suspended single droplets: experimental, theoretical and computational simulations," Rep. Prog. Phys. 76, 034601 (feb 2013).

[89] Kanakidou, M., Seinfeld, J. H., Pandis, S. N., Barnes, I., Dentener, F. J., Facchini, M. C., Van Dingenen, R., Ervens, B., Nenes, A., Nielsen, C. J., Swietlicki, E., Putaud, J. P., Balkanski, Y., Fuzzi, S., Horth, J., Moortgat, G. K., Winterhalter, R., Myhre, C. E. L., Tsigaridis, K., Vignati, E., Stephanou, E. G., and Wilson, J., "Organic aerosol and global climate modelling: a review," Atmos. Chem. Phys. 5, 1053-1123 (Mar. 2005).

[90] Andreae, M. O. and Crutzen, P. J., "Atmospheric aerosols: Biogeochemical sources and role in atmospheric chemistry," Science 276, 1052-1058 (may 1997).

[91] Jimenez, J. L., Canagaratna, M. R., Donahue, N. M., Prevot, A. S. H., Zhang, Q., Kroll, J. H., DeCarlo, P. F., Allan, J. D., Coe, H., Ng, N. L., Aiken, A. C., Docherty, K. S., Ulbrich, I. M., Grieshop, A. P., Robinson, A. L., Duplissy, J., Smith, J. D., Wilson, K. R., Lanz, V. A., Hueglin, C., Sun, Y. L., Tian, J., Laaksonen, A., Raatikainen, T., Rautiainen, J., Vaattovaara, P., Ehn, M., Kulmala, M., Tomlinson, J. M., Collins, D. R., Cubison, M. J., Dunlea, J., Huffman, J. A., Onasch, T. B., Alfarra, M. R., Williams, P. I., Bower, K., Kondo, Y., Schneider, J., Drewnick, F., Borrmann, S., Weimer, S., Demerjian, K., Salcedo, D., Cottrell, L., Griffin, R., Takami, A., Miyoshi, T., Hatakeyama, S., Shimono, A., Sun, J. Y., Zhang, Y. M., Dzepina, K., Kimmel, J. R., Sueper, D., Jayne, J. T., Herndon, S. C., Trimborn, A. M., Williams, L. R., Wood, E. C., Middlebrook, A. M., Kolb, C. E., Baltensperger, U., and Worsnop, D. R., "Evolution of organic aerosols in the atmosphere," Science 326(5959), 1525-1529 (2009).

[92] Longest, P. W. and Hindle, M., "Numerical model to characterize the size increase of combination drug and hygroscopic excipient nanoparticle aerosols," Aerosol Sci. Technol. 45(7), 884-899 (2011).

[93] Hindle, M. and Longest, P. W., "Condensational growth of combination drug-excipient submicrometer particles for targeted high-efficiency pulmonary delivery: evaluation of formulation and delivery device," J. Pharm. Pharmacol. 64(9), 1254-1263 (2012).

[94] Longest, P. W., McLeskey Jr., J. T., and Hindle, M., "Characterization of nanoaerosol size change during enhanced condensational growth," Aerosol Sci. Technol. 44(6), 473-483 (2010). PMID: 20640054.

[95] Nathanson, G. M., Davidovits, P., Worsnop, D. R., and Kolb, C. E., "Dynamics and kinetics at the gas-liquid interface," J. Phys. Chem. 100, 13007-13020 (jan 1996). 